Article

\title{
Synthesis of a New Titanate Coupling Agent for the Modification of Calcium Sulfate Whisker in Poly(Vinyl Chloride) Composite
}

\author{
Wenjin Yuan ${ }^{1,2}$, Yunhua $\mathrm{Lu}^{2}$ and Shiai $\mathrm{Xu}{ }^{1,2, *}$ \\ 1 School of Chemical Engineering, Qinghai University, Xining 810016, China; ywj407024846@126.com \\ 2 School of Materials Science and Engineering, East China University of Science and Technology, \\ Shanghai 200237, China; 18521399954@163.com \\ * Correspondence: saxu@ecust.edu.cn; Tel.: +86-971-5310274
}

Academic Editor: Volker Altstädt

Received: 27 May 2016; Accepted: 19 July 2016; Published: 28 July 2016

\begin{abstract}
A new titanate coupling agent synthesized from polyethylene glycol (PEG), isooctyl alcohol, and phosphorus pentoxide $\left(\mathrm{P}_{2} \mathrm{O}_{5}\right)$ was used for the modification of calcium sulfate whiskers (CSWs) and the preparation of high-performance CSW/poly(vinyl chloride) (PVC) composites. The titanate coupling agent (sTi) and the modified CSWs (sTi-CSW) were characterized by Fourier transform infrared (FTIR) spectroscopy, and the mechanical, dynamic mechanical, and heat resistant properties and thermostability of sTi-CSW/PVC and CSW/PVC composites were compared. The results show that sTi-CSW/PVC composite with $10 \mathrm{wt}$. \% whisker content has the best performance, and its tensile strength, Young's modulus, elongation at break, break strength, and impact strength are $67.2 \mathrm{MPa}$, $1926 \mathrm{MPa}, 233 \%$, $51.1 \mathrm{MPa}$, and $12.75 \mathrm{KJ} \cdot \mathrm{m}^{-2}$, with an increase of $20.9 \%, 11.5 \%, 145.3 \%, 24.6 \%$, and $65.4 \%$ compared to that of CSW /PVC composite at the same whisker content. As the whisker content increases, the storage modulus increases, the Vicat softening temperature decreases slightly, and the glass transition temperature increases at first and then decreases.
\end{abstract}

Keywords: poly(vinyl chloride) composites; calcium sulfate whisker; coupling agent; surface treatment; interface

\section{Introduction}

Poly(vinyl chloride) (PVC) is one of the most widely used general-purpose plastics, with a number of advantageous properties, such as good flame retardancy, corrosion resistance, and wear resistance [1]. It is generally classified into two types: rigid PVC with high strength and stiffness, and soft PVC with low-molecular-weight plasticizers that can greatly weaken the interactions between PVC chains [2]. The rigid PVC also has some intrinsic disadvantages, such as low impact strength and low resistance to microcrack propagation, thus severely limiting its applications as a high-performance structural material [3]. A variety of fillers have been incorporated into the PVC matrix to improve its performance (e.g., toughness, modulus, permeability, and heat resistance) and to reduce the production cost [4]. These fillers can be roughly divided into four types, according to their shapes: one-dimensional fillers (e.g., natural fibers [5,6], carbon nanotubes [7-9], and whiskers [10-12]), two-dimensional fillers (e.g., montmorillonite [13,14], graphene (G) [15-18], and graphene oxide [18]), three-dimensional fillers (e.g., $\mathrm{CaCO}_{3}$ particles $[19,20], \mathrm{SiO}_{2}$ particles $[21,22]$, and $\mathrm{TiO}_{2}$ particles $\left.[23,24]\right)$, and the compounds of different dimensional fillers (e.g., $\mathrm{Ag} / \mathrm{G}$ [17] and $\mathrm{TiO}_{2} / \mathrm{G}$ [25]). Calcium sulfate whisker (CSW) is a fiber-shaped single crystal with many desirable properties, such as high strength, high stiffness, and low cost [26], making it a desirable filler for the reinforcement of polymer composites.

However, the incorporation of most fillers, such as multiple-walled carbon nanotubes [27], $\mathrm{CaCO}_{3}$ particles [28], and nano- $\mathrm{TiO}_{2}$ particles [24], into the PVC matrix results in a decrease of the tensile 
strength of the composite. This is mainly because the interfacial interactions between the fillers and the polymer matrix are poor, and thus the stress applied to the composite cannot be transmitted sufficiently from the matrix to the fillers, leading to premature rupture of the composite [29]. Thus, the surface of the fillers needs to be modified to improve their wettability and adhesion with the polymer matrix [30]. This can be achieved with the use of appropriate coupling agents such as silane coupling agents [31,32], titanate coupling agents [33], and fatty acids [34]. However, a potential drawback of these commercial coupling agents is that they only have either polar or nonpolar groups on their chains.

The main purpose of this study is to synthesize a new titanate coupling agent having both polar and nonpolar groups, used for the modification of CSW. The polar groups have a strong interaction with the PVC matrix and thus can improve the interfacial interaction between CSW and the matrix, while the nonpolar groups can act as flexible chains to improve the toughness of the composite. Titanate coupling agent modified CSW (sTi-CSW)/PVC composite shows better tensile strength, stiffness, elongation at break, break strength, and impact strength than CSW / PVC composite. The toughness of PVC is significantly improved without a significant decrease of tensile strength.

\section{Results and Discussion}

\subsection{Fourier Transform Infrared (FTIR) Spectra of the Titanate Coupling Agent and sTi-CSW}

The structural formula of the target product is as follows:

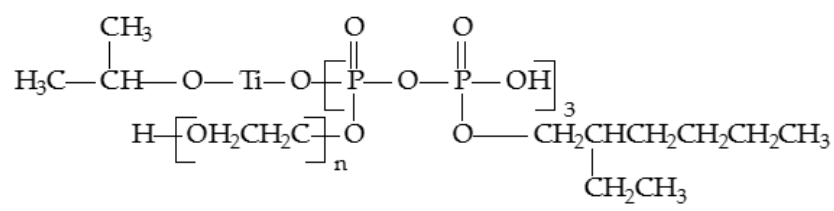

Figure 1 shows the FTIR spectra of the intermediate product (pyrophosphate) and the target product (titanate coupling agent). The absorption band at $724 \mathrm{~cm}^{-1}$ is assigned to the absorption of the $\mathrm{CH}_{2} \mathrm{CH}_{2} \mathrm{O}$ groups of polyethylene glycol (PEG), and the absorption intensity increases as the chain length increases. The absorption band at $2930 \mathrm{~cm}^{-1}$ is assigned to the stretching vibration of the $\mathrm{CH}_{3}$ and $\mathrm{CH}_{2}$ groups in isooctyl alcohol and that of the $\mathrm{CH}_{2}$ groups in $\mathrm{PEG}$, which is most indicative of the presence of PEG. The absorption band at $1360 \mathrm{~cm}^{-1}$ is assigned to the rocking vibration of $\mathrm{CH}_{2}$. The wide absorption band at $2564-2000 \mathrm{~cm}^{-1}$ is assigned to the characteristic absorption of $\mathrm{P}-\mathrm{O}-\mathrm{H}$ (broad peak at $2350 \mathrm{~cm}^{-1}$ ). The absorption band of pyrophosphate is between 1310 and $1210 \mathrm{~cm}^{-1}$, so the peak at $1250 \mathrm{~cm}^{-1}$ may be the absorption peak of that group. The peak at $1050 \mathrm{~cm}^{-1}$ is assigned to the characteristic absorption of $\mathrm{C}-\mathrm{O}$. The new absorption peaks at 613 and $698 \mathrm{~cm}^{-1}$ in line b are the absorption bands of Ti-O. These results imply that a new titanate coupling agent with both PEG and isooctyl alcohol segments has been successfully synthesized.

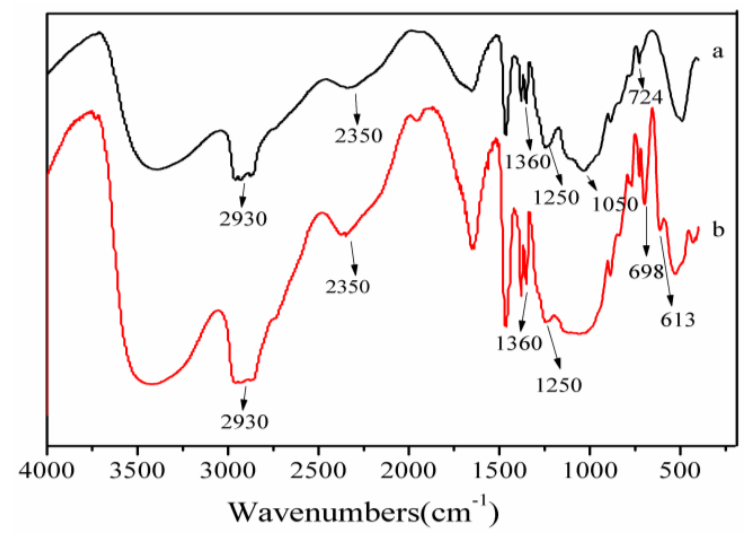

Figure 1. Fourier Transform Infrared (FTIR) spectra of (a) pyrophosphate and (b) self-synthesized titanate coupling agent. 
Figure 2 shows the FTIR spectra of CSW and sTi-CSW. When compared with CSW, two new absorption peaks are observed at 2930 and $2350 \mathrm{~cm}^{-1}$ in sTi-CSW, which are the characteristic absorption bands of the titanate coupling agent, and thus indicate the successful modification of CSW.

Figure 3 shows the modification mechanism of sTi-CSW. The alkoxy groups of the titanate coupling agent can easily hydrolyze and react with the hydroxyl groups of CSWs. Thus, the polar groups are grafted to CSWs, which can interact with polar PVC and thus improve the properties of the composite.

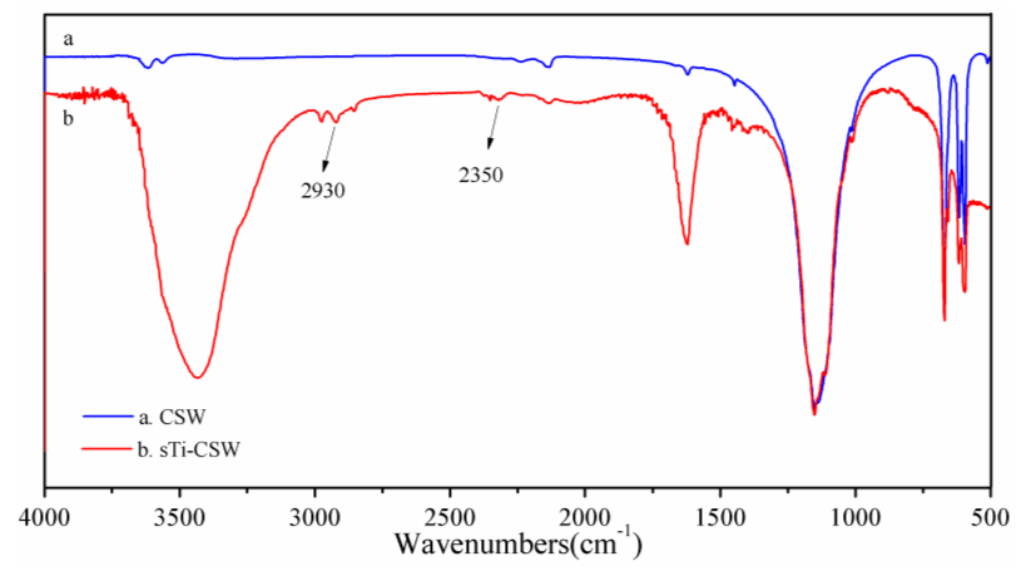

Figure 2. FTIR spectra of (a) calcium sulfate whisker (CSW) and (b) titanate coupling agent modified CSW (sTi-CSW).

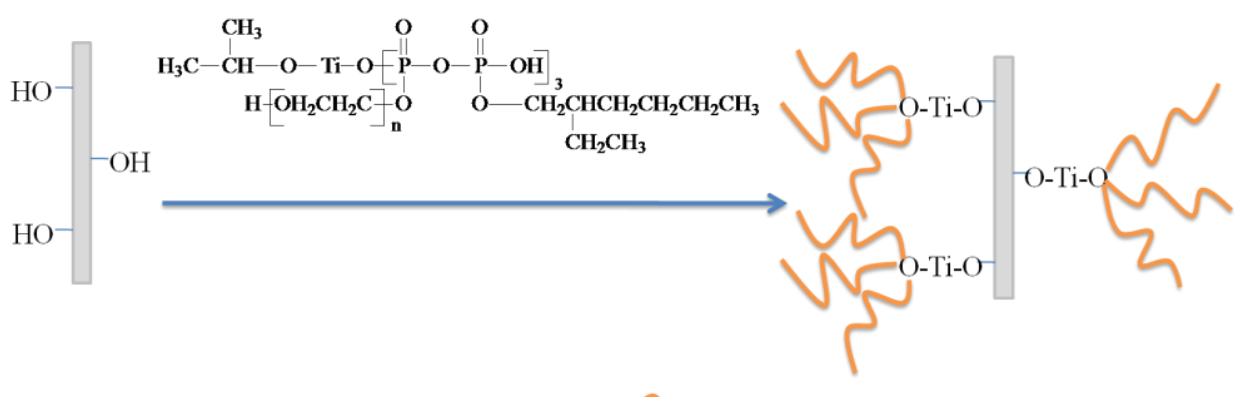

represent the organic functional group of sTi

Figure 3. The modification mechanism of sTi-CSW.

\subsection{Mechanical Performance}

Figure 4 shows that as the whisker content increases, the tensile strength of the CSW/PVC composite decreases, whereas that of sTi-CSW/PVC composite increases at first and then decreases. The tensile properties of sTi-CSW/PVC composite-especially the elongation at break-are obviously better than that of CSW/PVC composite. The elongation at break of CSW/PVC composite decreases rapidly with the increase of the whisker content, while that of sTi-CSW/PVC composite remains at a relatively high level with the increase of the whisker content up to $20 \mathrm{wt}$. \%, but decreases significantly with further increase of the whisker content to $30 \mathrm{wt}$. \%. The sTi-CSW/PVC composite has the best performance at $10 \mathrm{wt}$. \% whisker content. In this case, its tensile strength, Young's modulus, elongation at break, and break strength are $67.2 \mathrm{MPa}, 1926 \mathrm{MPa}, 233 \%$, and $51.1 \mathrm{MPa}$, with an increase of $20.9 \%$, $11.5 \%, 145.3 \%$, and $24.6 \%$ compared with that of CSW /PVC composite at the same whisker content. However, the tensile properties of sTi-CSW/PVC composite decrease significantly at 30 wt. \% whisker content. This may be because there is a percolation threshold of the filler content for the composite [35], exceeding which the fillers are more likely to collide with each other, thus leading to fracture or crumble 
of these fillers, and consequently the decrease of the reinforcing and toughening effects [2]. As a result, the mechanical properties of the composite decrease dramatically. In general, sTi-CSW can obviously improve the tensile properties of the composite. This may be due to the fact that the polar groups in the organic chain of the coupling agent have strong interactions with the PVC matrix, leading to the improvement of the interfacial bonding between the matrix and the whiskers [36,37], and that the flexible segments (the alkane and ether groups) of the coupling agent can act as a toughening agent, leading to the improvement of the elongation at break.

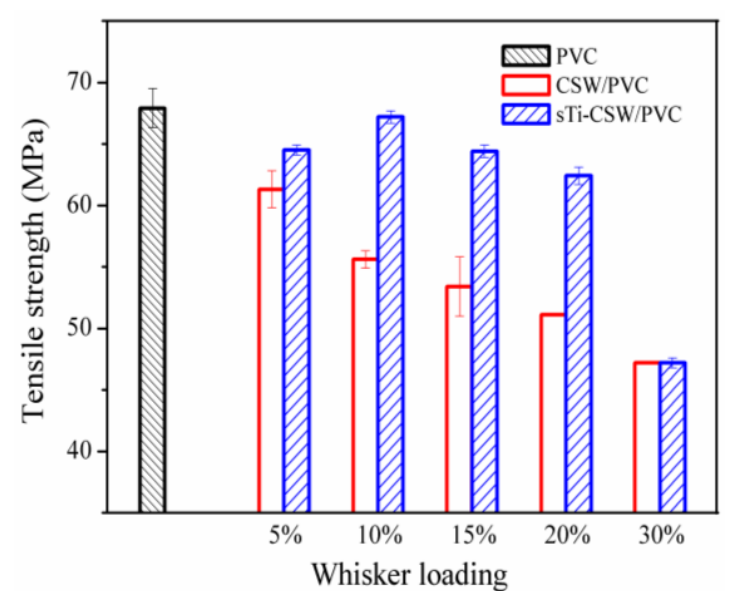

(a)

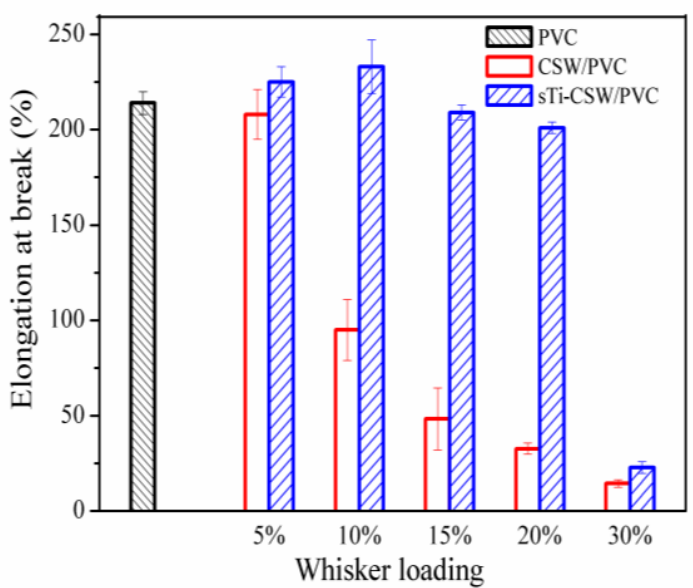

(c)

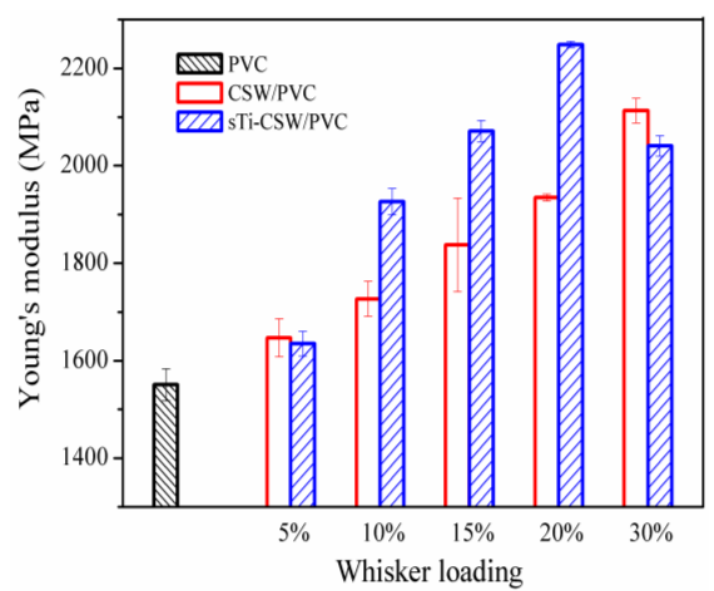

(b)

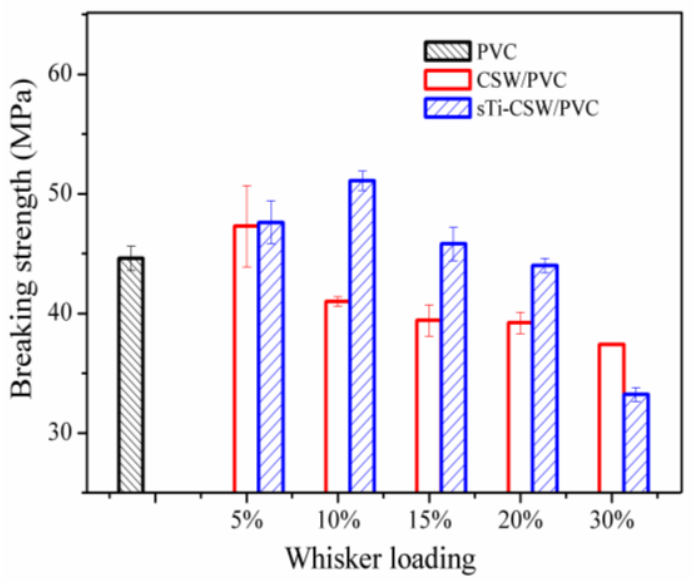

(d)

Figure 4. Mechanical properties (a) Tensile strength; (b) Young's modulus; (c) Elongation at break; (d) Breaking strength of CSW/PVC and sTi-CSW/PVC composites with various filler contents.

Figure 5 shows the Izod impact strength of CSW/PVC and sTi-CSW/PVC composites with different CSW contents. It can be seen that the impact strength is increased from $7.71 \mathrm{KJ} \cdot \mathrm{m}^{-2}$ for CSW / PVC to $12.75 \mathrm{KJ} \cdot \mathrm{m}^{-2}$ for sTi-CSW/PVC with $10 \mathrm{wt}$. \% CSWs. This may also be due to the combined effects of the flexible segments and the strong interfacial interaction. The impact strength of sTi-CSW / PVC composite also decreases rapidly at $30 \mathrm{wt}$. \% whisker content, which is consistent with the tensile properties. 


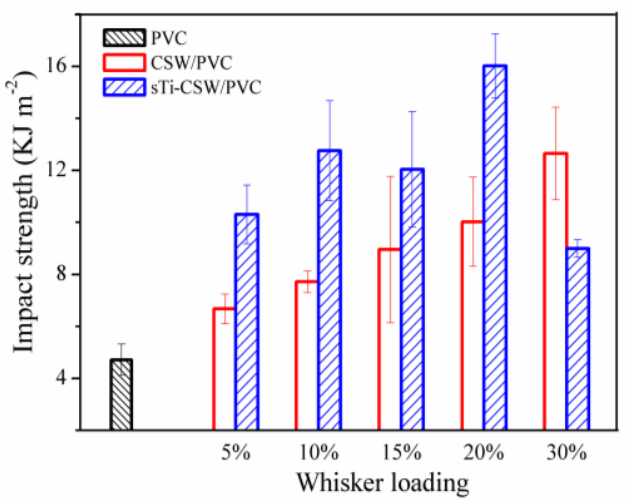

Figure 5. Impact strength of CSW/PVC and sTi-CSW/PVC composites with various filler contents.

\subsection{Interfacial Morphology}

Figure 6 shows the SEM images of the tensile fracture surfaces of CSW/PVC [38] and sTi-CSW/PVC composites with 5, 10, and $30 \mathrm{wt}$. \% CSWs. For CSW/PVC composite, pullouts and gaps between whiskers and PVC matrix are clearly observed, and the whiskers are more likely to agglomerate as their content increases. However, for sTi-CSW/PVC composite, the PVC matrix adheres tightly to the whiskers at 5 and $10 \mathrm{wt}$. \% whisker content. This may also be due to the strong interaction between the polar groups of the coupling agent and the PVC matrix, which can improve the interfacial properties of the composite [12]. Although the interfacial interaction between whiskers and matrix is still good at $30 \mathrm{wt}$. \% whisker content, the whisker size decreases due to collisions during the mixing process that may lead to the fracture of whiskers.
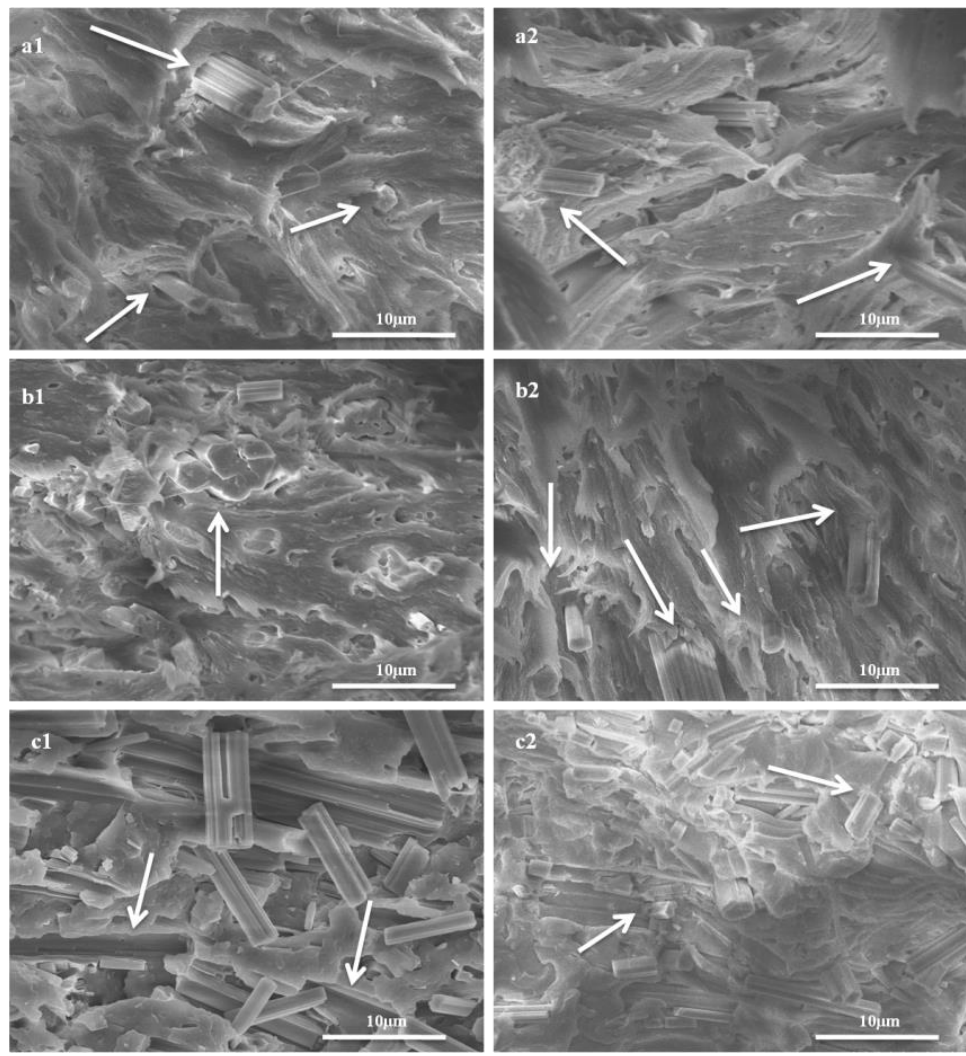

Figure 6. SEM images of the tensile fracture surfaces of CSW/PVC with (a1) 5 wt. \%; (b1) 10 wt. \% and (c1) 30 wt. \% whisker (Thanks for the permission from J. Mater. Sci. Technol.); and sTi-CSW/PVC with (a2) 5 wt. \%; (b2) 10 wt. \% and (c2) 30 wt. \% whisker. 


\subsection{Dynamic Mechanical Properties}

The thermomechanical properties of sTi-CSW/PVC composite with different whisker contents-including storage modulus $\left(E^{\prime}\right)$, loss modulus $\left(E^{\prime \prime}\right)$, and tangent $\delta(\tan \delta)$-were determined by dynamic mechanical analysis (DMA), and the results are shown in Figures 7-9, respectively. Figure 7 shows that at low temperatures, the storage modulus of sTi-CSW/PVC composite increases with increasing whisker content, except at $30 \mathrm{wt}$ \% \% whisker content. Besides, it is much higher than that of CSW/PVC composite at the same whisker content (Table 1), indicating that the titanate coupling agent can efficiently improve the interfacial interaction between whiskers and PVC matrix [39]. This allows the whiskers to effectively restrict the deformation of the matrix, thus resulting in the improvement of the performance of the composite [40,41].

Figures 8 and 9 show that the peak temperature of the composite increases at first and then decreases with the increase of the whisker content. The glass transition temperature of sTi-CSW/PVC and CSW/PVC composites are listed in Table 2. For sTi-CSW/PVC composite, the glass transition temperature reaches a maximum at $10 \mathrm{wt}$. \% whisker content, and then decreases with further packing of whiskers, probably due to the presence of both polar organic groups and nonpolar flexible alkane chains in the coupling agent. The polar groups have strong interactions with the PVC matrix, which can prevent the PVC matrix from deforming at high temperatures and improve the glass transition temperature of the composite. However, the alkane chains and the ether groups are flexible, which can decrease the glass transition temperature.

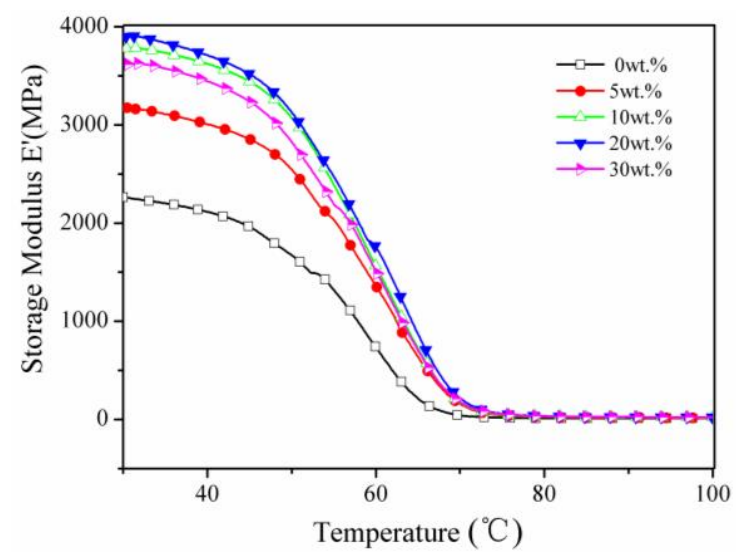

Figure 7. Storage modulus as a function of temperature for sTi-CSW/PVC composites with different whisker contents.

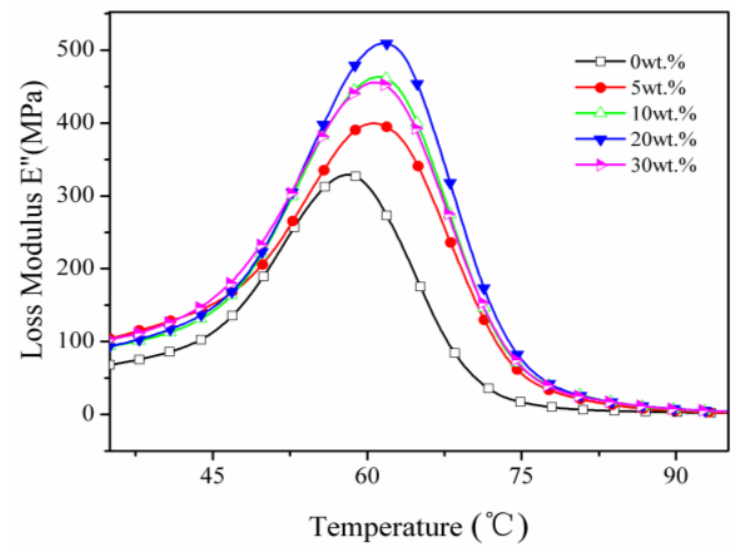

Figure 8. Loss modulus as a function of temperature for sTi-CSW/PVC composites with different whisker contents. 


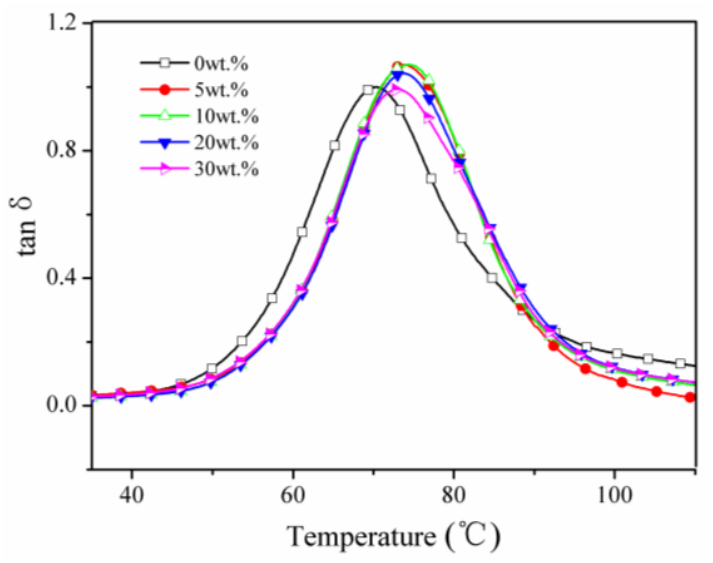

Figure 9. Tan $\delta$ as a function of temperature for sTi-CSW/PVC composites with different whisker contents.

Table 1. The storage modulus (MPa) of CSW/PVC and sTi-CSW/PVC composites at $30{ }^{\circ} \mathrm{C}$.

\begin{tabular}{cccccc}
\hline Whisker Content (\%) & $\mathbf{0}$ & $\mathbf{5}$ & $\mathbf{1 0}$ & $\mathbf{2 0}$ & $\mathbf{3 0}$ \\
\hline CSW/PVC & 2263 & 2760 & 2871 & 2929 & 3540 \\
sTi-CSW/PVC & 2263 & 3172 & 3780 & 3900 & 3616 \\
\hline
\end{tabular}

Table 2. Glass transition temperature $\left({ }^{\circ} \mathrm{C}\right)$ of $\mathrm{CSW} / \mathrm{PVC}$ and sTi-CSW/PVC composites.

\begin{tabular}{cccccc}
\hline Whisker Content (\%) & $\mathbf{0}$ & $\mathbf{5}$ & $\mathbf{1 0}$ & $\mathbf{2 0}$ & $\mathbf{3 0}$ \\
\hline CSW/PVC & 70.3 & 70.4 & 73.0 & 74.3 & 74.4 \\
sTi-CSW/PVC & 70.3 & 73.8 & 74.4 & 73.8 & 72.9 \\
\hline
\end{tabular}

\subsection{Heat Resistance Property}

Vicat softening temperatures (VST) reflect the moving ability of chain segments. The more difficult it is for the chain segments to move, the higher the VST will be [42]. Figure 10 shows the VST of CSW / PVC and sTi-CSW/PVC composites with various filler contents. It can be seen that as the whisker content increases, the VST of both CSW / PVC and sTi-CSW/PVC composites increases, because these whiskers can effectively restrict the mobility of the PVC segments due to their large length-to-diameter ratio [43]. However, the VST of the sTi-CSW/PVC composite is slightly lower than that of the CSW/PVC composite, due to the flexible chains in the coupling agent.

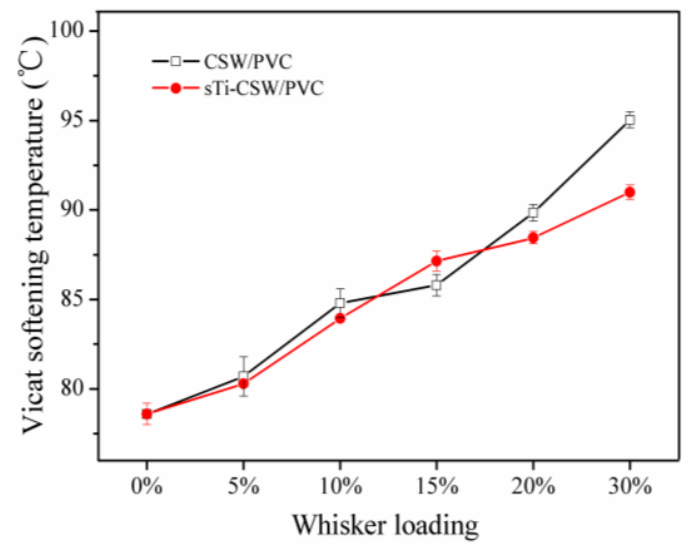

Figure 10. Vicat softening temperature (VST) for CSW/PVC and sTi-CSW/PVC composites with various filler contents. 


\subsection{Thermal Properties}

The thermogravimetric analysis (TGA) and differential thermogravimetry (DTG) curves of pristine PVC, CSW/PVC, and sTi-CSW/PVC composites are shown in Figures 11 and 12, respectively. It shows that there are two weight loss stages for pristine PVC, CSW/PVC, and sTi-CSW/PVC composites. The first decomposition stage starts at about $276{ }^{\circ} \mathrm{C}$ and ends at about $298{ }^{\circ} \mathrm{C}$, which can be attributed to the dehydrochlorination that may induce double bonds along the polymer chain and lead to conjugated polymer chains [44]. However, the sample becomes thermally stable again at $298-435^{\circ} \mathrm{C}$ due to the formation of conjugated double bonds after $\mathrm{HCl}$ evolution [45]. A second decomposition stage occurs at $435-489^{\circ} \mathrm{C}$, which corresponds to the polyacetylene cracking (scission of covalent and multiple bonds). A stable residue (i.e., carbon black) is formed at temperatures greater than $489^{\circ} \mathrm{C}$ [46].

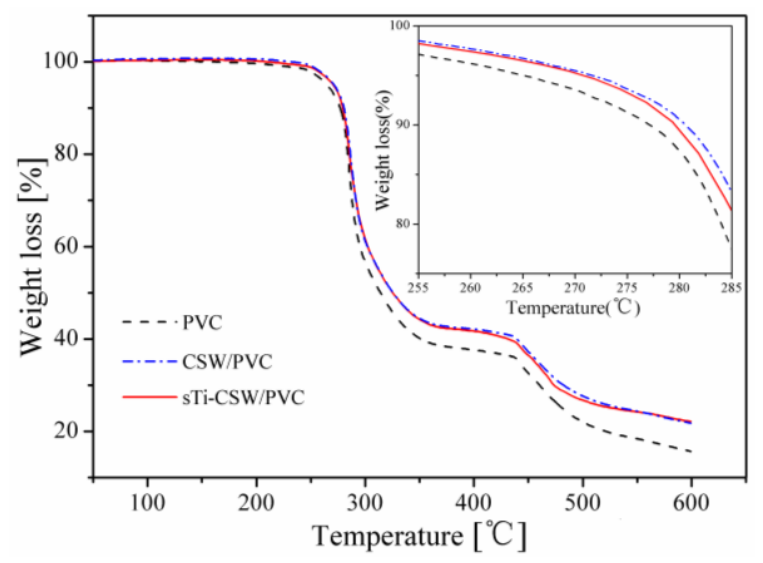

Figure 11. Thermogravimetric analysis (TGA) curves of PVC and its composites.

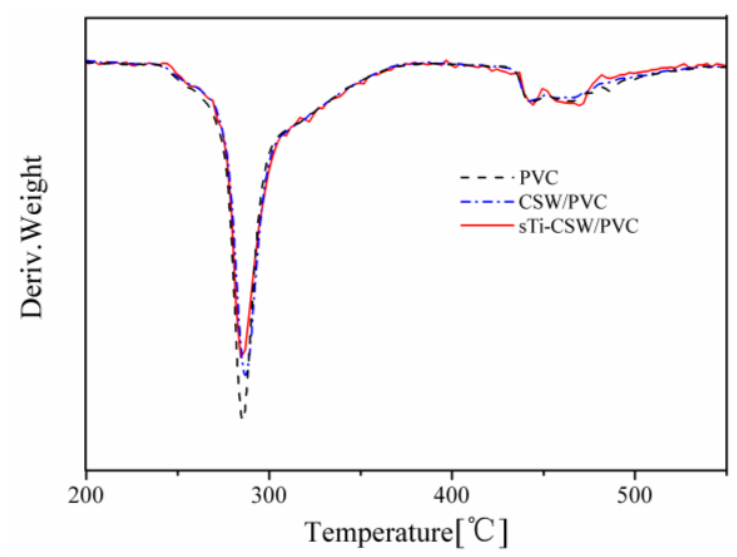

Figure 12. Differential thermogravimetry (DTG) curves of PVC and its composites.

The temperatures of onset decomposition $\left(\mathrm{T}_{\text {onset }}\right)$, rapidest decomposition $\left(\mathrm{T}_{\mathrm{rpd}}\right)$, and $50 \%$ weight loss residue $\left(\mathrm{T}_{50}\right)$ are summarized in Table 3 . It can be seen that the $\mathrm{T}_{\text {onset }}$ and $\mathrm{T}_{\mathrm{rpd}}$ of sTi-CSW/PVC composite are quite close to that of CSW/PVC composite and pristine PVC, indicating no significant improvement of thermal degradation in CSW/PVC and sTi-CSW/PVC composites [12]. The TGA curve of sTi-CSW /PVC composite is almost coincident with that of CSW/PVC composite, and their $\mathrm{T}_{50}$ values are higher than that of pristine PVC, indicating that the thermal stability of both sTi-CSW/PVC and CSW/PVC composites are improved to a certain degree [46,47]. However, the thermal stability of the composite cannot be further improved by sTi-CSW. 
Table 3. Degradation temperatures of PVC and its composites obtained from the TGA and DTG curves.

\begin{tabular}{cccc}
\hline \multirow{2}{*}{ Sample } & \multicolumn{3}{c}{ Temperature $\left.{ }^{\circ} \mathbf{C}\right)$} \\
\cline { 2 - 4 } & $\mathbf{T}_{\text {onset }}$ & $\mathbf{T}_{\mathbf{r p d}}$ & $\mathbf{T}_{\mathbf{5 0}}$ \\
\hline Pristine PVC & 276 & 285 & 314 \\
CSW $/$ PVC & 277 & 286 & 325 \\
sTi-CSW/PVC & 277 & 285 & 325 \\
\hline
\end{tabular}

The content of CSW in all composites is 5 wt. \%.

\section{Materials and Methods}

\subsection{Materials}

$\mathrm{P}_{2} \mathrm{O}_{5}$ (analytically pure), isooctyl alcohol (chemically pure) and dichloroethane (analytically pure) were purchased from Shanghai Lingfeng Reagent Co., Ltd. (Shanghai, China). Titanium isopropoxide was purchased from Aladdin Reagent Co., Ltd. (Shanghai, China). PEG 200 (chemically pure) was purchased from Sinopharm Chemical Reagent Co., Ltd. (Shanghai, China). PVC (SG-5) was purchased from Dongguan Dansheng Plastic Materials Co., Ltd. (Dongguan, China). CSWs were purchased from Shanghai Fengzhu Trading Co., Ltd. (Shanghai, China). Organic tin, dioctyl phthalate (DOP), glyceryl monosterate (GMS), acrylic processing aid (ACR) and paraffin wax were commercially available, all of which were of technical grade.

\subsection{Preparation}

\subsubsection{Synthesis of Polar Polyether Titanate Coupling Agent}

Pyrophosphate was prepared as follows: $2.1 \mathrm{~g}$ of $\mathrm{P}_{2} \mathrm{O}_{5}$ and $40 \mathrm{~mL}$ of dichloromethane solvent were added sequentially into a $250 \mathrm{~mL}$ three-necked round-bottom flask fitted with a mechanical overhead stirrer, and stirred rapidly. Then, $5.28 \mathrm{~g}$ of isooctyl alcohol and $4 \mathrm{~g}$ of PEG 200 were added slowly, the mixture was stirred at $60^{\circ} \mathrm{C}$ for $2 \mathrm{~h}$, and excess solvent was removed by vacuum distillation. The obtained transparent liquid was pyrophosphate.

Then, $1.6 \mathrm{~g}$ of titanium isopropoxide and $30 \mathrm{~mL}$ of dichloromethane solvent were added sequentially into a $250 \mathrm{~mL}$ three-necked round-bottom flask, and $8 \mathrm{~g}$ of pyrophosphate was added dropwise. The temperature of the water bath was maintained at $20-55^{\circ} \mathrm{C}$. The mixture was stirred at $75{ }^{\circ} \mathrm{C}$ for $2.5 \mathrm{~h}$ and then heated to $90^{\circ} \mathrm{C}$ to complete the reaction and to remove excess solvent. The obtained light yellow and viscid liquid was the titanate coupling agent.

\subsubsection{Preparation of sTi-CSW and sTi-CSW/PVC Composites}

sTi-CSWs were prepared as follows: $1.5 \mathrm{~g}$ of sTi was pre-hydrolysed in $95 \mathrm{wt}$. \% ethanol solution, and $50 \mathrm{~g}$ of dried CSWs were added sequentially into a $500 \mathrm{~mL}$ three-necked round-bottom flask fitted with a mechanical overhead stirrer. The mixture was stirred at $75{ }^{\circ} \mathrm{C}$ for $4 \mathrm{~h}$, and then the obtained products were dried under vacuum at $100{ }^{\circ} \mathrm{C}$ for $2 \mathrm{~h}$ to remove excess water.

sTi-CSW / PVC composites were prepared as described in our previous study [12]: PVC resin (100 phr) was mixed with various contents of CSW or sTi-CSW using organic tin (2 phr) as the heat stabilizer and DOP (4 phr) as the plasticizer. GMS (0.6 phr), ACR (4 phr), and paraffin wax (0.4 phr) were then added. All PVC constitutes were mixed uniformly and then processed using a two-roll mill at $170{ }^{\circ} \mathrm{C}$. The resultant compound was molded into rectangular sheets by compression molding at $170{ }^{\circ} \mathrm{C}$ and $10 \mathrm{MPa}$ for $5 \mathrm{~min}$ using a plate vulcanizing press.

\subsection{Characterization}

\subsubsection{Fourier Transform Infrared (FTIR) Spectroscopy}

The FTIR spectra of the titanate coupling agent and sTi-CSW were recorded using a Nicolet 6700 FTIR spectrometer (Thermo Fisher, New York, NY, USA) with a scan number of 32 and a resolution of $4 \mathrm{~cm}^{-1}$. 


\subsubsection{Mechanical Properties}

The tensile properties of CSW/PVC and sTi-CSW/PVC composites were determined on a MTS E44 universal testing machine (MTS Industrial Systems, Shenzhen, China) in accordance with ISO 527 [48], and the notched impact strength was determined on a CEAST 9050 tester (CEAST, Turin, Italy) according to ISO 179 [49]. The means and standard deviations were calculated from at least five independent tests for each sample.

\subsubsection{Scanning Electron Microscopy}

The fracture surfaces of the tensile samples were characterized by scanning electron microscopy (SEM, S-4800, Hitachi, Tokyo, Japan). Prior to SEM observation, the fracture surfaces were coated with a thin gold layer.

\subsubsection{Dynamic Mechanical Analysis}

The dynamic properties of CSW/PVC and sTi-CSW/PVC composites were determined on a TA Instruments Q800 (TA instruments, New Castle, DE, USA) in three-point bending mode. A single specimen of each composite type was tested at a vibration frequency of $1 \mathrm{~Hz}$ and heated from 25 to $140{ }^{\circ} \mathrm{C}$ at a heating rate of $3^{\circ} \mathrm{C} / \mathrm{min}$.

\subsubsection{Heat Resistance Analysis}

Vicat softening temperatures (VST) were measured using a VST tester (ZWK1302-B, MTS, Shenzhen, China) according to ISO 306:2004 [50]. The test load was $10 \mathrm{~N}$ and the heating rate was $120^{\circ} \mathrm{C} / \mathrm{h}$.

\subsubsection{Thermogravimetric Analysis}

Thermogravimetric analysis (TGA) was carried out at a heating rate of $10^{\circ} \mathrm{C} / \mathrm{min}$ to $600^{\circ} \mathrm{C}$ under a nitrogen atmosphere using a Netzsch STA 409PC thermogravimetric analyzer.

\section{Conclusions}

A new polar organic coupling agent having both polar and nonpolar (alkane and ether) groups has been successfully synthesized in this study. The polar groups can improve the interfacial interactions between the whiskers and the PVC matrix, while the non-polar groups can improve the toughness of the composites, thus resulting in a significant improvement of the mechanical properties of the sTi-CSW/PVC composites. The tensile strength, Young's modulus, elongation at break, break strength, and impact strength of sTi-CSW/PVC composite with $10 \mathrm{wt}$. \% whisker are $67.2 \mathrm{MPa}, 1926 \mathrm{MPa}$, $233 \%, 51.1 \mathrm{MPa}$, and $12.75 \mathrm{KJ} \mathrm{m}^{-2}$, with an increase of $20.9 \%, 11.5 \%, 145.3 \%, 24.6 \%$, and $65.4 \%$, respectively, as compared with that of CSW/PVC composite with the same whisker content. There is a strong interfacial interaction between the modified whiskers and the PVC matrix. The DMA results show that the storage modulus is also obviously improved. The glass transition temperature increases at first and then decreases with the increase of the whisker content. However, no obvious improvement is observed in the heat resistant property and the thermal stability, which may be due to the flexible groups of the coupling agent. In general, the coupling agent synthesized in this study can effectively improve the toughness of PVC without significantly decreasing its tensile properties. Thus, this coupling agent may have important applications in the modification of inorganic fillers.

Acknowledgments: This research is financially supported by the National Natural Science Foundation of China (U 1507123), the Foundation from Qinghai Science and Technology Department (2014-HZ-817) and Kunlun Scholar Award Program of Qinghai Province.

Author Contributions: Wenjin Yuan did the experiments, data analysis and wrote the paper. Shiai Xu reviewed and revised the manuscript of this paper. Yunhua Lu contributed to the data analysis.

Conflicts of Interest: The authors declare no conflict of interest. 


\section{References}

1. Fu, S.Y.; Feng, X.Q.; Lauke, B.; Mai, Y.W. Effects of particle size, particle/matrix interface adhesion and particle loading on mechanical properties of particulate-polymer composites. Compos. Part B Eng. 2008, 39, 933-961. [CrossRef]

2. Wang, H.; Xie, G.; Yang, C.; Zheng, Y.; Ying, Z.; Ren, W.; Zeng, Y. Enhanced toughness of multilayer graphene filled poly(vinyl chloride) composites prepared using melt-mixing method. Polym. Compos. 2015. [CrossRef]

3. Yanagase, A.; Ito, M.; Yamamoto, N.; Ishikawa, M. Effect of modifier characteristics on toughness of poly (vinyl chloride). J. Appl. Polym. Sci. 1996, 62, 1387-1393. [CrossRef]

4. Wang, H.; Xie, G.; Ying, Z.; Tong, Y.; Zeng, Y. Enhanced Mechanical Properties of Multi-layer Graphene Filled Poly(vinyl chloride) Composite Films. J. Mater. Sci. Technol. 2015, 31, 340-344. [CrossRef]

5. El-Shekeil, Y.A.; Sapuan, S.M.; Jawaid, M.; Al-Shuja'a, O.M. Influence of fiber content on mechanical, morphological and thermal properties of kenaf fibers reinforced poly(vinyl chloride)/thermoplastic polyurethane poly-blend composites. Mater. Design 2014, 58, 130-135. [CrossRef]

6. Petchwattana, N.; Covavisaruch, S.; Pitidhammabhorn, D. Influences of water absorption on the properties of foamed poly(vinyl chloride)/rice hull composites. J. Polym. Res. 2013. [CrossRef]

7. Mkhabela, V.J.; Mishra, A.K.; Mbianda, X.Y. Thermal and mechanical properties of phosphorylated multiwalled carbon nanotube/polyvinyl chloride composites. Carbon 2011, 49, 610-617. [CrossRef]

8. Yazdani, H.; Smith, B.E.; Hatami, K. Multi-walled carbon nanotube-filled polyvinyl chloride composites: Influence of processing method on dispersion quality, electrical conductivity and mechanical properties. Compos. Part A 2016, 82, 65-77. [CrossRef]

9. Yu, B.; Xu, X. Conductive properties and mechanism of polyvinyl chloride doped by a multi-walled carbon nanotube-polypyrrole nano-complex dopant. RSC Adv. 2014, 4, 3966-3973. [CrossRef]

10. Chen, L.; Hong, Y.; Zhang, Y.; Qiu, J. Fabrication of polymer matrix composites reinforced with controllably oriented whiskers. J. Mater. Sci. 2000, 35, 5309-5312. [CrossRef]

11. Chazeau, L.; Cavaille, J.; Terech, P. Mechanical behaviour above Tg of a plasticised PVC reinforced with cellulose whiskers; a SANS structural study. Polymer 1999, 40, 5333-5344. [CrossRef]

12. Yuan, W.; Cui, J.; Cai, Y.; Xu, S. A novel surface modification for calcium sulfate whisker used for reinforcement of poly(vinyl chloride). J. Polym. Res. 2015, 22. [CrossRef]

13. Sterky, K.; Jacobsen, H.; Jakubowicz, I.; Yarahmadi, N.; Hjertberg, T. Influence of processing technique on morphology and mechanical properties of PVC nanocomposites. Eur. Polym. J. 2010, 46, 1203-1209. [CrossRef]

14. Madaleno, L.; Schjødt-Thomsen, J.; Pinto, J.C. Morphology, thermal and mechanical properties of PVC/MMT nanocomposites prepared by solution blending and solution blending+melt compounding. Compos. Sci. Technol. 2010, 70, 804-814. [CrossRef]

15. Vadukumpully, S.; Paul, J.; Mahanta, N.; Valiyaveettil, S. Flexible conductive graphene/poly(vinyl chloride) composite thin films with high mechanical strength and thermal stability. Carbon 2011, 49, 198-205. [CrossRef]

16. Yao, K.; Tan, H.; Lin, Y.; Zhang, G.; Gong, J.; Qiu, J.; Tang, T.; Na, H.; Jiang, Z. Effect of polystyrene long branch chains on melt behavior and foaming performance of poly(vinyl chloride)/graphene nanocomposites. RSC Adv. 2014, 4, 64053-64060. [CrossRef]

17. Saadatabadi, N.M.; Nateghi, M.R.; Borhanizarandi, M. Fabrication and characterization of nanosilver intercalated graphene embedded poly(vinyl chloride)composite thin films. J. Polym. Res. 2014, 21. [CrossRef]

18. Deshmukh, K.; Khatake, S.M.; Joshi, G.M. Surface properties of graphene oxide reinforced polyvinyl chloride nanocomposites. J. Polym. Res. 2013, 20. [CrossRef]

19. Kemal, I.; Whittle, A.; Burford, R.; Vodenitcharova, T.; Hoffman, M. Toughening of unmodified polyvinylchloride through the addition of nanoparticulate calcium carbonate. Polymer 2009, 50, 4066-4079. [CrossRef]

20. Xie, X.L.; Liu, Q.X.; Li, K.Y.; Zhou, X.P.; Zhang, Q.X.; Yu, Z.Z.; Mai, Y.W. Rheological and mechanical properties of $\mathrm{PVC} / \mathrm{CaCO}_{3}$ nanocomposites prepared by in situ polymerization. Polymer 2004, 45, 6665-6673. [CrossRef]

21. Conradi, M.; Zorko, M.; Jerman, I.; Orel, B.; Verpoest, I. Mechanical properties of high density packed silica/poly (vinyl chloride) composites. Polym. Eng. Sci. 2013, 53, 1448-1453. [CrossRef] 
22. Zhu, A.; Cai, A.; Zhou, W.; Shi, Z. Effect of flexibility of grafted polymer on the morphology and property of nanosilica/PVC composites. Appl. Surf. Sci. 2008, 254, 3745-3752. [CrossRef]

23. Zhang, Z.; Wang, S.; Zhang, J. Large stabilizing effect of titanium dioxide on photodegradation of PVC/ $\alpha$-methylstyrene-acrylonitrile copolymer/impact modifier-matrix composites. Polym. Compos. 2014, 35, 2365-2375. [CrossRef]

24. Zhang, Y.X.; Song, Y.H.; Zheng, Q. Mechanical and thermal properties of nanosized titanium dioxide filled rigid poly(vinyl chloride). Chin. J. Polym. Sci. 2012, 31, 325-332. [CrossRef]

25. Feng, X.; Xing, W.; Song, L.; Hu, Y.; Liew, K.M. TiO 2 loaded on graphene nanosheet as reinforcer and its effect on the thermal behaviors of poly(vinyl chloride) composites. Chem. Eng. J. 2015, 260, 524-531. [CrossRef]

26. Wang, Y.; Li, Y.; Yuan, A.; Yuan, B.; Lei, X.; Ma, Q.; Han, J.; Wang, J.; Chen, J. Preparation of calcium sulfate whiskers by carbide slag through hydrothermal method. Cryst. Res. Technol. 2014, 49, 800-807. [CrossRef]

27. Wang, G.; Qu, Z.; Liu, L.; Shi, Q.; Guo, J. Study of SMA graft modified MWNT/PVC composite materials. Mater. Sci. Eng. A 2008, 472, 136-139. [CrossRef]

28. Zeng, X.F.; Wang, W.Y.; Wang, G.Q.; Chen, J.F. Influence of the diameter of $\mathrm{CaCO}_{3}$ particles on the mechanical and rheological properties of PVC composites. J. Mater. Sci. 2008, 43, 3505-3509. [CrossRef]

29. Kim, H.; Miura, Y.; Macosko, C.W. Graphene/Polyurethane Nanocomposites for Improved Gas Barrier and Electrical Conductivity. Chem. Mater. 2010, 22, 3441-3450. [CrossRef]

30. Altan, M.; Yildirim, H. Mechanical and Antibacterial Properties of Injection Molded Polypropylene $/ \mathrm{TiO}_{2}$ Nano-Composites: Effects of Surface Modification. J. Mater. Sci. Technol. 2012, 28, 686-692. [CrossRef]

31. Sun, S.; Li, C.; Zhang, L.; Du, H.; Burnell-Gray, J. Effects of surface modification of fumed silica on interfacial structures and mechanical properties of poly (vinyl chloride) composites. Eur. Polym. J. 2006, 42, 1643-1652. [CrossRef]

32. Yun, S.; Song, Q.; Zhao, D.; Qian, G.; Li, X.; Li, W. Study on the inorganic-organic surface modification of potassium titanate whisker. Appl. Surf. Sci. 2012, 258, 4444-4448. [CrossRef]

33. Wah, C.A.; Choong, L.Y.; Neon, G.S. Effects of titanate coupling agent on rheological behaviour, dispersion characteristics and mechanical properties of talc filled polypropylene. Eur. Polym. J. 2000, 36, 789-801. [CrossRef]

34. Osman, M.A.; Atallah, A. Surfactant Chain Length and Tensile Properties of Calcium Carbonate-Polyethylene Composites. Macromol. Chem. Phys. 2007, 208, 87-93. [CrossRef]

35. Patil, C.B.; Kapadi, U.R.; Hundiwale, D.G.; Mahulikar, P.P. Preparation and characterization of poly(vinyl chloride) calcium carbonate nanocomposites via melt intercalation. J. Mater. Sci. 2009, 44, 3118-3124. [CrossRef]

36. Zhang, H. Effect of a novel coupling agent, alkyl ketene dimer, on the mechanical properties of wood-plastic composites. Mater. Design 2014, 59, 130-134. [CrossRef]

37. Hu, J.; Jia, X.; Li, C.; Ma, Z.; Zhang, G.; Sheng, W.; Zhang, X.; Wei, Z. Effect of interfacial interaction between graphene oxide derivatives and poly(vinyl chloride) upon the mechanical properties of their nanocomposites. J. Mater. Sci. 2014, 49, 2943-2951. [CrossRef]

38. Yuan, W.; Xu, S. Mechanical properties and interfacial interaction of modified calcium sulfate whisker/poly(vinyl chloride) composites. J. Mater. Sci. Technol. 2016. accepted.

39. Auad, M.L.; Mosiewicki, M.A.; Uzunpinar, C.; Williams, R.J.J. Single-wall carbon nanotubes/epoxy elastomers exhibiting high damping capacity in an extended temperature range. Compos. Sci. Technol. 2009, 69, 1088-1092. [CrossRef]

40. Lian, M.; Fan, J.; Shi, Z.; Li, H.; Yin, J. Kevlar ${ }^{\circledR}$-functionalized graphene nanoribbon for polymer reinforcement. Polymer 2014, 55, 2578-2587. [CrossRef]

41. Abu-Abdeen, M. Static and dynamic mechanical properties of poly(vinyl chloride) loaded with aluminum oxide nanopowder. Mater. Design 2012, 33, 523-528. [CrossRef]

42. Yang, L.; Sun, D.; Li, Y.; Liu, G.; Gao, J. Properties of poly(vinyl chloride) blended with an emulsion copolymer of N-cyclohexylmaleimide and methyl methacrylate. J. Appl. Polym. Sci. 2003, 88, 201-205. [CrossRef]

43. Yu, T.; Li, Y.; Ren, J. Preparation and properties of short natural fiber reinforced poly(lactic acid) composites. Trans. Nonferrous Metal. Soc. 2009, 19, s651-s655. [CrossRef]

44. Djidjelli, H.S.T.; Benachour, D. Effect of plasticizer nature and content on the PVC stability and dielectric properties. J. Appl. Polym. Sci. 2000, 78, 685-691. [CrossRef] 
45. Benavides, R.C.B.; Castañeda, A.O.; López, G.M.; Arias, G. Different thermo-oxidative degradation routes in poly(vinyl chloride). Polym. Degrad. Stable 2001, 73, 417-423. [CrossRef]

46. Bishay, I.K.; Abd-El-Messieh, S.L.; Mansour, S.H. Electrical, mechanical and thermal properties of polyvinyl chloride composites filled with aluminum powder. Mater. Design 2011, 32, 62-68. [CrossRef]

47. Li, X.; Lei, B.; Lin, Z.; Huang, L.; Tan, S.; Cai, X. The utilization of bamboo charcoal enhances wood plastic composites with excellent mechanical and thermal properties. Mater. Design 2014, 53, 419-424. [CrossRef]

48. Plastics. Determination of Tensile Properties; BS EN ISO 527-1:2012; The British Standards Institution: London, UK; 31; March; 2012.

49. Plastics. Determination of Charpy Impact Properties; BS EN ISO 179-1:2010; The British Standards Institution: London, UK; 31; July; 2010.

50. Plastics. Thermoplastic Materials—Determination of Vicat Softening Temperature; BS EN ISO 306:2004; The British Standards Institution: London, UK; 5; October; 2004.

(C) 2016 by the authors; licensee MDPI, Basel, Switzerland. This article is an open access article distributed under the terms and conditions of the Creative Commons Attribution (CC-BY) license (http://creativecommons.org/licenses/by/4.0/). 